DOI 10.37882/2223-2982.2022.01.01

\title{
МЫШЛЕНИЕ ДЕТЕЙ СТАРШЕГО ДОШКОЛЬНОГО ВОЗРАСТА С ЗАДЕРЖКОЙ ПСИХИЧЕСКОГО РАЗВИТИЯ
}

\section{THINKING OF OLDER PRESCHOOL CHILDREN WITH MENTAL RETARDATION \\ E. Bagnetova \\ N. Kapustina}

Summary: The main violation in the structure of the defect of children with mental retardation is the lack of formation of analytical and synthetic activity. Modern regulatory and legal foundations of the education system impose requirements for the individualization of the educational process. This is also reflected in the requirements for the diagnostic examination procedure. We have developed a diagnostic program that includes a number of tasks. This article summarizes the empirical results of the psychological and pedagogical examination of preschoolers (6-7 years old) with mental retardation. During the diagnostic process, the peculiarities of the formation of mental operations were revealed, such as: analysis, synthesis, comparison, generalization, classification. Empirical data confirm a number of theoretical and methodological positions of leading researchers in the field of special psychology and pedagogy (U.V. Ulenkova, N.A. Tsypina, C.G. Shevchenko, L.M. Shipitsyna, etc.). This proves the existence of an urgent problem of education and training of children with mental retardation and emphasizes the importance of planning correctional and pedagogical work on the development of mental activity in students of this category.

Keywords: thinking, mental operations, psychological and pedagogical examination, experiment, mental retardation, diagnostic program.

\author{
Багнетова Екатерина Михайловна \\ Аспирант, преподаватель, БУ «Сургутский \\ государственный педагогический университет» \\ KateRinaaaa_23@mail.ru \\ Капустина Наталья Геннадьевна \\ к.n.н., дочент, БУ «Сургутский государственный \\ педагогический университет» \\ haushen@mail.ru
}

Аннотация: Основным нарушением в структуре дефекта детей с задержкой психического развития является несформированность аналитико-синтетической деятельности. Современные нормативно-правовые основы системы образования предъявляют требования к индивидуализации образовательного процесса. Это отображается и в требованиях к процедуре диагностического обследования. Нами была разработана диагностическая программа, включающая в себя ряд заданий. В данной статье обобщены полученные эмпирические результаты психолого-педагогического обследования дошкольников (6-7 лет) с задержкой психического развития. В процессе диагностики были выявлены особенности сформированности мыслительных операций, таких как: анализ, синтез, сравнение, обобщение, классификация. Эмпирические данные подтверждают ряд теоретико-методологических положений ведущих исследователей в области специальной психологии и педагогики (У.В. Ульенковой, Н.А. Цыпиной, С.Г. Шевченко, Л.М. Шипицыной и др.). Это доказывает существование актуальной проблемы воспитания и обучения детей с задержкой психического развития и подчеркивает важность планирования коррекционно-педагогической работы по развитию мыслительной деятельности у обучающихся данной категории.

Ключевые слова: мышление, мыслительные операции, психолого-педагогическое обследование, эксперимент, задержка психического развития, диагностическая программа.

го развития, но, как отмечают Емелина Д.А. и Макаров И.В., она преодолима при соответствующей грамотной психолого-педагогической коррекционной работе, которая должна быть обязательно начата еще в дошкольном периоде.[3]

Исследователи отмечают, что дети с ЗПР представляют собой крайне разнородную группу, включающие как разную этиологию, так и проявления данного вида психического дизонтогенеза. согласно данным разных авторов (Баряева Л.Б., Защиринская О.В., Соколова Е.В.), в структуре дефекта при ЗПР вперед выдвигается замедленное развитие интеллектуальных процессов с неярко выраженными интеллектуальными нарушениями и незрелость эмоционально-волевой сферы.

Ведущим в структуре дефекта является нарушение мыслительной деятельности. Мыслительная деятельность состоит из мыслительных операций, которые 
направлены на решение конкретных задач, а также мыслительные операции позволяют закладывать картину воспринимаемого мира. Мыслительные операции (анализ, синтез, сравнение, обобщение, классификация) интегрируются с другими высшими психическими фикциями, а степень их участия в протекающих процессах определяет актуальный уровень развития дошкольника.

Именно поэтому для оценки ситуации развития необходимо выявить актуальный уровень сформированности операций анализа, синтеза, сравнения, классификации, обобщения. В связи с этим считаем, что развитие мыслительных операций у детей старшего дошкольного возраста с ЗПР является первоочередной задачей коррекционно-педагогической деятельности.

Необходимо отметить, что вопросы изучения мышления дошкольников уже поднимались в психологопедагогических исследованиях. Но исследовался этот вопрос в аспекте либо подготовки детей к школьному обучению (Фадина Г.В., Шустов Е.А.) [8,10], либо в плане математического образования дошкольников с ЗПР (Баряева Л.Б.) [2]. Стрекалова Т.А. [7] изучала формирование логического мышления у дошкольников с задержкой психического развития дошкольного возраста с ЗПР, которые представлены в исследованиях Н.В. Елфимовой, Й.Н. Брокане, С.А. Домишкевича и В.А. Пермяковой, 3.М. Дунаевой.

В последние годы произошло накопление и переосмысление фактов об особенностях детей дошкольного возраста с ЗПР. В первую очередь подчеркивается полиморфность и системность нарушения (Бабкина Н.В., Баряева Л.Б., Защиринская О.В. и др.) [1,5]. В ПРАООП [6] для детей с ЗПР отмечается: «...к моменту поступления в школу дети с ЗПР не достигают необходимого уровня психологической готовности за счет незрелости мыслительных операций...» (с. 16). В связи с чем представляется необходимым определить отличительные черты мыслительных операций у детей старшего дошкольного возраста с ЗПР. Кроме того, необходимо установить, какие условия воспитания и обучения способствуют коррекции мыслительных операций. Решение этих вопросов позволит раскрыть возможности и пути компенсаторного развития мышления у детей с ЗПР еще в дошкольном возрасте, что важно для успешного обучения в начальном звене школы.

Экспериментальное выявление особенностей развития мыслительных операций у старших дошкольников с ЗПР являлось целью нашего констатирующего эксперимента.

Эксперимент проводился среди 10 обучающихся с диагнозом «Парциальная недостаточность» на основе заключения территориальной психолого-медико-педагогической комиссии в возрасте 6-7 лет. Из них 6 мальчиков и 4 девочки. Трое из группы детей обладают отягощённым анамнезом развития. У остальных семерых отмечена неотягощённая картина анамнеза. Родители воспитанников отмечают, что 8 из 10 дошкольников часто болели в детстве респираторными заболеваниями. Матери воспитанников сообщают о том, что беременность протекала спокойно, роды проходили без осложнений. У большинства родителей это второй или третий по счету ребенок.

В процессе исследовательской деятельности использовалась разработанная диагностическая программа с авторскими методиками С.Д. Забрамной [4], О.В.Боровик, БелопольскойН.Л., Н.Я.Семаго, М.М.Семаго, А.Я. Ивановой, В.И. Векслера, Дж.К. Равена. Рассмотрим полученные результаты.

\section{Методика І. «Классификация предметов» (С.А. Забрамная, О.В. Боровик)}

Данная методика направлена на выявление умений осуществлять группировку на основе обобщающих знаний с учетом ведущих признаков объединения объектов. Обработка полученных данных показала, что у детей с ЗПР умения классификации сформированы в неполном объеме. Только трое детей (30\%) показало высокий уровень выполнения данного задания. Были предложены родовые группы: «Домашние животные», «Дикие животные», «Перелетные птицы», «Зимующие птицы», «Посуда», «Мебель», «Одежда», «Обувь». Все эти лексические темы, соответствуют содержанию программного материала, изучаемого в дошкольных образовательных организациях в рамках освоения АООП ДО для детей с ЗПР. Основная трудность, выявленная в ходе выполнения данного диагностического задания, - это не владение родовыми понятиями. Самые сложные для классифицирования оказались «Перелетные и зимующие птицы», «Домашние и дикие животные». Дети путали группы и выполняли задание методом проб и ошибок, поэтому основная масса (пятеро детей) показала низкий уровень (50\%). При демонстрации умений классифицировать объекты по группам, они основывались на несущественные признаки. Ваня от деятельности отказался, на любые попытки педагога включить его в деятельность реагировал негативизмом. Средний уровень продемонстрировали двое детей (20\%). Аня и Кирилл допустили единичные ошибки, самостоятельно выполняли задания, но испытывали некоторые затруднения при классификации «Обуви и одежды». Педагог оказывал помощь в виде наводящих и уточняющих вопросов. Дети помощь принимали и выполняли задание, руководствуясь помощью взрослого. 


\section{Методика 2. «Иск^ючение предметов»} (Белопольская Н.^.)

Данная методика направлена на выявление актуального уровня сформированности процессов обобщения, сравнения; протекания процессов анализа и синтеза.

Предлагаемы стимульный материал состоит из 28 карточек, на каждой из которой изображены четыре предмета. На трех предметах имеется общий признак, а у одного он отсутствует. Задания поделены на 7 групп по степени усложнения: от простого к сложному (от Группы I к Группе VI).

Респонденты продемонстрировали следующие результаты: высокий уровень отмечен у одного ребенка с 3ПР (10\%), средний уровень выявлен у двух (20\%) детей и низкий у семерых детей, что составило $70 \%$.

В ходе выполнения диагностического обследования нами зафиксированы следующие особенности выполнения задания у детей с низким уровнем: трудности поиска лишнего предмета групп с IV-Vl; многие дети при выборе лишнего предмета показывали любую картинку, лишь бы завершить процедуру диагностики; при вопросе «Правильно! А теперь объясни, почему ты так решил?» не было правильно аргументированного ответа. Это свидетельствует о том, что диагностированы качественные патологические особенности, к которым относится снижение и искажение уровня обобщения.

В авторской методике подчеркивается, что испытуемый не должен получать от экспериментатора какую-либо обратную связь о правильности решаемых задач, это позволит объективно оценить полученные результаты. Для детей с ЗПР методика была адаптирована и предлагалась пустая карточка, чтобы закрыть лишний предмет, т. к. наглядно-действенное форма заданий способствует лучшему решению задач. Это фиксировалось в протоколе. Дети, продемонстрировавшие высокие и средние результаты, приняли эту форму работы и справились с заданием. Главная трудность у Вики и Ани (средний уровень) - это аргументационная позиция выбранного предмета. Ответы были неполными, неточными. Например, при выполнении задания из 4 группы (IV-3 - напитки и мороженое), Аня сказала: «Мороженое пьют». Виктор, показавший высокий уровень при выполнении этого задания мог развёрнуто и полно аргументировать позицию, но быстро утомлялся. Именно поэтому задание было разбито на блоки и выполнялось в течение дня.

Субъект 8. Последовательные картинки В.И. Векслер и методика «Складывание разрезных картинок» (Семаго H.Я., Семаго М.М.) направлены на выявление сформиро- ванности процессов анализа и синтеза, способности к конструктивному праксису, а также владение навыками пространственной координации.

Если рассматривать полученные результаты при складывании разрезных картинок, то дети продемонстрировали высокий уровень и средний. Воспитанники со средним уровнем испытывали трудности при складывании картинки, разрезанной нестандартным способом (например, по диагонали).

При выполнении диагностической методики В.И. Векслера были выделено четверо дошкольников с низким уровнем (40\%) и шесть детей (60\%) со среднем уровнем. Были отмечены следующие феномены выполнения: переворачивание картинок в хаотичном порядке; нелогичная, непоследовательная сюжетная линия; непонимание выстраиваемой ситуации; не желание выполнять задание; излишняя болтливость не содержанию картин.

\section{Методика 6. «Нелепишы» (С.А. Забрамная, О.В. Боровик)}

Диагностическое задание позволяет выявить сформированные представления и образы об окружающем мире, об уровне выстраивания причинно-следственных связей, умение рассуждать. В решение данной методики дети с ЗПР продемонстрировали 7 детей (70\%) низкий уровень и трое (30\%) средний уровень. Дошкольники действовали импульсивно при рассматривании картин. Многие дети реагировали неадекватно на предъявляемый материал: громко смеялись, швыряли картинки. Кирилл, выполнивший заданий на среднем уровне, очень долго рассматривал картины и только потом давал ответы. Многим детям была необходима помощь, но не все ее принимали. Например, Матвей закрывал сразу уши.

\section{Методика исследования обучаемости А.Я. Ивановой}

В ходе процедуры проведения исследования было выявлено трое дошкольников с высокой обучаемостью: активная ориентировка, направленная на познание новых объектов, умственное выстраивание плана предстоящей деятельности, принятие помощи, демонстрируют перенос усвоенных знаний. Дети с ЗПР, входящие в промежуточную группу, были выявлены в количестве трех дошкольников. В треть, крайнюю группу вошло четверо обучающихся с ЗПР, которые продемонстрировали слабую обучаемость, низкую мотивационную и познавательную заинтересованность, несамостоятельны, неактивны. Основной особенностью логического переноса является частичный перенос в наглядно-действенной форме. Один из воспитанников проявил полное отсутствие переноса. 


\section{Матришы Аж.К. Равена}

В процессе проведения диагностического задания были получены следующие результаты процентной шкалы степени развития интеллекта: $\mathrm{V}$ степень была выявлена у двоих респондентов, IV степень у пятерых дошкольников и у троих детей с ЗПР был выявлений средний интеллект (III степень). При выполнении задания обследуются навыки анализа и синтеза, умение сравнивать, выстраивать аналогии. В каждой из серий карточки построены по принципу от простого к сложному. Для детей с ЗПР это задание оказалось самым трудным, т.к. основной дефект - нарушение мыслительной деятельности.
Таким образом, основываясь на экспериментальных данных, можно сделать вывод, что у детей старшего дошкольного возраста с задержкой психического развития снижена мыслительная деятельность, преобладает недостаточный уровень мотивации и обучаемости. Вследствие этого одно из необходимых условий образования обучающихся данной категории является обеспечение кадровым составом для организации коррекционноразвивающей работы с целью развития мыслительных операций, коррекции познавательной активности и самостоятельности, а также повышение мотивационного компонента деятельности, с помощью специальных методов, приемов, технологий.

\section{ЛИТЕРАТУРА}

1. Бабкина Н.В. Психологическое сопровождение ребенка с задержкой психического развития: монография / Н.В. Бабкина, И.А. Коробейников; Министерство просвещения Российской Федерации, Федеральное государственное бюджетное научное учреждение "Институт коррекционной педагогики Российской академии образования". - Москва: Наука, 2020. - 212, [1] с.: ил., табл.; ISBN 978-5-02-040806-7

2. Баряева Л.Б. Интегративная модель математического образования дошкольников с задержкой психического развития /Л.Б. Баряева; Диссертация на соискание ученой степени доктора педагогических наук- Москва, 2005.

3. Емелина Д.А., Макаров И.В. Задержки психического развития у детей (аналитический обзор) Обозрение психиатрии и медицинской психологии/Д.А. Емелин, И.В. Макаров; Обозрение психиатрии и медицинской психологии - № 1, 2018.

4. Забрамная, С.Д. Психолого-педагогическая диагностика умственного развития детей [Текст] / С.Д. Забрамная. - М.: Просвещение, Владос. - 2008

5. Защиринская 0.В. Психология детей с задержкой психического развития: учебное пособие / 0.В. Защиринская; Санкт-Петербургский гос. ун-т. - Москва: Изд. дом Санкт-Петербургского гос. ун-та, 2019. - 166 с.; ISBN 978-5-288-05940-7.

6. Примерная Адаптированная Основная Образовательная программа дошкольного образования детей с ЗПР

7. Стрекалова Татьяна Александровна. Формирование логического мышления у дошкольников с задержкой психического развития.: диссертация ... кандидата психологических наук: 19.00.10. - Москва, 1982. - 166 с...

8. Фадина Галина Валерьевна. Формирование интеллектуально-эмоциональной готовности детей с задержкой психического развития к школьному обучению: диссертация ... кандидата педагогических наук: 13.00.01. - Саратов, 2001. - 194 с.

9. Н.В. Филиппова, Ю.Б. Барыльник, Е.В. Бачило, А.С. Исмайлова Эпидемиология нарушений психического развития в детском возрасте/ Филиппова Н.В., Барыльник Ю.Б., Бачило Е.В., Исмайлова А.С. Российский психиатрический журнал №6, 2015 г.

10. Шустов, Евгений Александрович. Технология формирования школьной готовности детей с задержкой психического развития, воспитывающихся в дошкольных образовательных учреждениях: диссертация ... кандидата педагогических наук: 13.00.03. - Шадринск, 2000. - 175 с.

11. Chvjakin V.A., Kiseleva N.S. Psychology of children with mental retardation: Training handbook. M.: MRSEl, 2014: 92 p. (in Russian)

12. Vlasova T.A., Lebedinskaja K.S. Actual problems of clinical study of mental retardation in children. Defektologiya [Defectology]. 1975; Vol. 6: 8-17. (in Russian) 